\title{
Do pregnant women use pharmacological treatment as prescribed?
}

\author{
Beau de Korte ${ }^{1}$, Nori Smeets ${ }^{1}$, Angela Colbers ${ }^{1}$, Bart van den Bemt ${ }^{1}$, and Marleen van \\ Gelder $^{1}$ \\ ${ }^{1}$ Radboudumc
}

February 11, 2022

\begin{abstract}
Aim: Pregnant women are hypothesized to have low adherence to prescribed medication, because of concerns about toxicity and harmful effects on the unborn child. However, very little is known about the actual adherence to prescribed medication during pregnancy. We determined to what extent women follow treatment recommendations regarding prescribed medication use in mid-pregnancy. Methods: Dutch women participating in the PRIDE Study completed a six-week diary on medication use. Additionally, pharmacy records were obtained. For each medication dispensed, we determined three measures of adherence: 1) whether use was reported in the diary (actual use), 2) difference between dispensing date and date of first reported use (initiation time), and 3) proportion of days with at least the correct number of doses taken (implementation adherence). Results: During the six-weeks study period, 235 of 816 women (29\%) were prescribed medication. Actual use was highest for medications used for chronic conditions ( $88 \%$; $95 \%$ confidence interval [95\% CI] 81-93), followed by medication for pregnancy-related conditions (79\%; 95\% CI 71-86) and medication for occasional and short-time use (69\%; 95\% CI 60-77). We observed a [?]1 day delay in treatment initiation for $42 \%$ of medications dispensed for the first time in the study period. For medications that were actually used, mean implementation adherence was 74.2\% (95\% CI 69.3-79.2). Conclusion: Although actual use of medications dispensed was high, many pregnant women did not adhere to treatment recommendations. This non-adherence may impact maternal and child health and lead to exposure misclassification in studies in perinatal pharmacoepidemiology relying on administrative databases.
\end{abstract}

\section{Do pregnant women use pharmacological treatment as prescribed?}

Running title: Adherence to prescribed medication in pregnancy

Beau A C de Korte ${ }^{1,2}$, Nori J L Smeets ${ }^{3}$, Angela Colbers ${ }^{4}$, Bart J F van den Bemt ${ }^{4,5}$, Marleen M H J van Gelder $^{1}$

${ }^{1}$ Department for Health Evidence, Radboud Institute for Health Sciences, Radboud university medical center, Nijmegen, The Netherlands

${ }^{2}$ Department of Gynecology, Canisius Wilhelmina Hospital, Nijmegen, The Netherlands

${ }^{3}$ Department of Pharmacology and Toxicology, Radboud Institute for Health Sciences, Radboud university medical center, Nijmegen, The Netherlands

${ }^{4}$ Department of Pharmacy, Radboud Institute for Health Sciences, Radboud university medical center, Nijmegen, The Netherlands

${ }^{5}$ Department of Rheumatology Research, Sint Maartenskliniek, Nijmegen, The Netherlands

Corresponding author: Marleen van Gelder PhD, Department for Health Evidence (HP133), Radboudumc, P.O. Box 9101, 6500 HB Nijmegen, The Netherlands. T: +31-24-3666126. E: Marleen.vanGelder@radboudumc.nl. 
Data availability: The data from this study are not publicly available due to privacy and ethical restrictions. For further requests about access to PRIDE Study data please contact Marleen.vanGelder@radboudumc.nl.

Funding: No specific funding was received for this paper.

Author contributions: Ms de Korte was the lead author, responsible for study design, statistical analysis, data interpretation, and preparation of the draft manuscript. Ms Smeets was responsible for study design, data collection, data interpretation, and critically reviewed the manuscript. Dr. Colbers and Prof. van den Bemt were responsible for study design, data interpretation, and critically reviewed the manuscript. Dr. van Gelder was responsible for study design, data collection, statistical analysis, data interpretation, and critically reviewed the manuscript.

Conflict of interest: The authors have stated explicitly that there are no conflicts of interest in connection with this paper.

Ethics approval : The PRIDE Study was approved by the Regional Committee on Research Involving Human Subjects Arnhem-Nijmegen (CMO 2009/305).

ORCID ID : Nori Smeets 0000-0002-4927-2459

Angela Colbers 0000-0002-0389-9934

Bart van den Bemt 0000-0002-8560-9514

Marleen van Gelder 0000-0003-4853-4434

Key words: Medication adherence; Implementation; Pregnancy; PRIDE Study; Treatment initiation

Word count: 3,032

Table count: 4

Figure count: 3

\section{BULLET POINT SUMMARY}

What is already known about this subject

- Non-adherence to pharmacological treatment during pregnancy may lead to maternal and fetal complications.

- Adherence is considered low during pregnancy, but definitions and methods to determine adherence differed between studies.

- Maternal questionnaires and interviews are prone to underreporting, resulting in unfairly low estimates of adherence when being compared to prescription databases.

\section{What this study adds}

- Many pregnant women did not adhere to treatment recommendations regarding dosage and therapy duration.

- Implementation adherence was high for medications for chronic conditions, but substantially lower for medications for short-term use and pregnancy-related medication.

- Our findings emphasize the need for identification of reasons for this behavior and associated preventive measures.

\section{ABSTRACT}

Aim: Pregnant women are hypothesized to have low adherence to prescribed medication, because of concerns about toxicity and harmful effects on the unborn child. However, very little is known about the 
actual adherence to prescribed medication during pregnancy. We determined to what extent women follow treatment recommendations regarding prescribed medication use in mid-pregnancy.

Methods: Dutch women participating in the PRIDE Study completed a six-week diary on medication use. Additionally, pharmacy records were obtained. For each medication dispensed, we determined three measures of adherence: 1) whether use was reported in the diary (actual use), 2) difference between dispensing date and date of first reported use (initiation time), and 3) proportion of days with at least the correct number of doses taken (implementation adherence).

Results: During the six-weeks study period, 235 of 816 women (29\%) were prescribed medication. Actual use was highest for medications used for chronic conditions (88\%; 95\% confidence interval [95\% CI] 81-93), followed by medication for pregnancy-related conditions (79\%; 95\% CI 71-86) and medication for occasional and short-time use $(69 \% ; 95 \%$ CI $60-77)$. We observed a [?]1 day delay in treatment initiation for $42 \%$ of medications dispensed for the first time in the study period. For medications that were actually used, mean implementation adherence was $74.2 \%$ (95\% CI 69.3-79.2).

Conclusion: Although actual use of medications dispensed was high, many pregnant women did not adhere to treatment recommendations. This non-adherence may impact maternal and child health and lead to exposure misclassification in studies in perinatal pharmacoepidemiology relying on administrative databases.

\section{INTRODUCTION}

Non-adherence to pharmacological treatment is a significant global public health issue, as it is estimated that half of patients do not take their medication as prescribed [1,2]. Medication adherence is defined as the extent to which medication-intake behavior corresponds with the medication regimen agreed upon with the healthcare professional [1]. Among pregnant women, non-adherence can result in or facilitate the onset of maternal and fetal complications, enhance risks of hospitalization, and subsequently increase healthcare costs $[2,3]$. Women tend to overestimate the teratogenic risk of medication [4-6], resulting in reluctance to use medication during pregnancy due to these concerns [6-9]. Incorrect perception of the safety of medication use during pregnancy is widespread [10], and leads to caution among treating physicians in prescribing medication as well [11-13].

Previous studies generally indicate low adherence to prescribed medication during pregnancy, but methods and definitions differed substantially between studies. When comparing dispensing data to self-reported medication use, only $43 \%$ of all medications dispensed were reported to be used by Danish pregnant women, with notable differences between medications for chronic conditions (70-100\%) and medications used for local or short-term treatment (12-77\%) [14]. Similarly, in a Dutch cohort study among pregnant women concordance between self-reported medication use and pharmacy records was moderate to good for medications used for chronic conditions, whereas concordance was low for medications that are used occasionally [15]. Instead of using a self-administered questionnaire to verify actual use of prescribed medication, De Jonge et al. conducted telephone interviews, showing that $84-92 \%$ of mothers confirmed taking the medication, but slightly more than half of the medications were used at the prescribed dose and for the duration prescribed $[16]$.

Establishing the extent to which pregnant women are adherent to their medication is challenging. Methods that rely on self-reported medication use, including questionnaires and interviews, are prone to underreporting [17-22], resulting in unfairly low estimates of adherence when being compared to prescription databases. More reliable methods, such as electronic drug monitoring, pill counts, and detection of medication in biological samples, are often not feasible in large-scale studies because of high costs and logistical challenges. Nevertheless, more insight into adherence to pharmacological treatment among pregnant women is needed not only to improve pharmacotherapy outcomes, but also to guide studies on medication safety during pregnancy, which increasingly rely on administrative healthcare databases and registries [23]. Therefore, we aimed to determine to what extent women adhere to treatment recommendations regarding prescribed medication during pregnancy using diaries as the reference standard, which are less prone to underreporting compared to methods that rely on recall over a longer period of time [24, 25]. 


\section{METHODS}

\section{Study population}

This study was imbedded in an ongoing prospective cohort study among Dutch pregnant women, the PRegnancy and Infant DEvelopment (PRIDE) Study. The aim of the PRIDE Study is to identify factors that may influence the health of women and their offspring during and after pregnancy. In short, pregnant women aged [?]18 years were invited for participation by their prenatal care providers at their first prenatal care visit, through the 'Moeders voor Moeders' initiative, or online advertisements. The median gestational age at enrollment was 9.9 weeks. Participants were asked to complete web-based questionnaires at enrollment, gestational weeks 17 and 34, and biannually after delivery. Furthermore, consent was asked to obtain records from prenatal care providers and pharmacists. A detailed description of the PRIDE Study can be found elsewhere [26]. For the current study, we selected all PRIDE Study participants with ongoing pregnancies who completed the first follow-up questionnaire at gestational week 17 between September 2013 and February $2018(\mathrm{~N}=4,851)$.

The PRIDE Study was approved by the Regional Committee on Research Involving Human Subjects Arnhem-Nijmegen (CMO 2009/305). Women were asked to participate on a completely voluntary basis and gave their informed consent digitally through the Internet.

\section{Ascertainment of medication use}

In the first follow-up questionnaire at gestational week 17, participants were asked to complete a 6 -weeks paper-based medication diary during gestational weeks 19-24 or 26-31 [22]. Through these diaries, participants reported on the exact name of the medication used, daily dose, and specific dates of use. To decrease participant burden, participants could write down the name of any medication used on a daily basis on the first page of the diary. A reminder was sent if the diary was not returned within two weeks after the last day covered by the diary.

In the Netherlands, most people visit only one or two pharmacies and all pharmacies use computerized dispensing records. Through the 'Landelijk Schakelpunt', to which $96 \%$ of Dutch pharmacies are connected [27], information on medications dispensed is exchanged between pharmacies, making their dispensing records virtually complete. For PRIDE Study participants who provided consent, data on medications dispensed in the three months before pregnancy until six months after the estimated date of delivery were requested from the pharmacies the women reported visits to. From these records, we abstracted data on medications with use in the 6 -weeks covered by the medication diary, including name of the medication, start and stop dates, frequency of use, and dosage prescribed.

Medications were coded using the Anatomical Therapeutic Chemical (ATC) classification system [28]. We excluded vaccines (ATC code J06 and J07) and vitamins (A11, A12, B03B), as these may not be considered as medication by the participants. Furthermore, medications that are predominantly used over-the counter (acetaminophen [N02BE01], antacids [A02AD01], and xylometazoline [R01AA07]) and medications not indicated for use during pregnancy (contraceptives [G03A], fertility medication [G03CA and G03GA], and tranexamic acid [B02AA02]) were excluded. We classified the medications in three mutually exclusive categories after the classification of Bakker et al. [29]: (1) medication for chronic conditions, (2) medications for occasional and short-time use, and (3) pregnancy-related medication (Supplemental Table 1). Medications for chronic conditions did not necessarily have to be taken on a regular or daily basis, but may have been used on an as-needed basis as well.

\section{Medication adherence}

Adherence to prescribed medications was assessed with three measures. Actual use was defined as a dispensed medication of which use was reported in the diary. The definitions of initiation and implementation as described by the ABC European adherence initiative taxonomy were used [30]. For medications first dispensed in the diary period (i.e. no use in the three months preceding the diary period according to the pharmacy records), we assessed non-initiation and initiation time (difference between dispensing date 
and date of first reported use in the diary). Implementation adherence was calculated as the proportion of days with at least the correct number of doses taken, with the pharmacy records as reference standard. Medications that were prescribed on an as-needed basis were excluded from the analyses on initiation and implementation.

\section{Other variables}

Maternal characteristics included age, level of education, net monthly household income, chronic conditions (asthma, chronic hypertension, depression, pre-existing diabetes, and thyroid disorders), pre-pregnancy body mass index (BMI), parity, smoking in pregnancy, and alcohol consumption in pregnancy. These data were available from the PRIDE Study questionnaires.

\section{Statistical analysis}

We described maternal characteristics of women who were dispensed at least one of the selected medications during the 6-weeks diary period and women who did not use medication according to the pharmacy records. For each medication registered in the pharmacy records with theoretical use in the diary period, we determined actual use with Wilson score 95\% confidence intervals (CIs), initiation, and implementation adherence for the three predefined medication categories, medication groups, and individual medications with [?]5 prescription dispensings. For implementation adherence, we calculated the mean proportion of days with at least the correct number of doses taken as well as the proportion of users with an implementation adherence [?] $80 \%$. To evaluate whether the maternal characteristics were associated with implementation adherence, we used univariable linear regression with robust standard errors to account for multiple prescriptions per participant in an exploratory analysis. All statistical analyses were performed using Stata version 16.0 (StataCorp LLC, College Station, TX).

\section{RESULTS}

Of the 4,851 PRIDE Study participants who completed the first follow-up questionnaire in the study period, $1,516(31.3 \%)$ completed the medication diary (Figure 1). Among participants with a completed medication diary, 1,275 (84.1\%) gave permission to request pharmacy records. Pharmacy records including start and stop dates of medication were obtained from 816 participants (64.0\%). Characteristics of the study population and excluded PRIDE Study participants are shown in Supplemental Table 2.

According to the pharmacy records, 235 (28.8\%) participants used at least one of the selected medications during the 6 -weeks diary period. These participants were slightly older, more often had a low/intermediate level of education, a net household income of $<\backslash$ euro3,500 per month, and a chronic condition, had a higher pre-pregnancy BMI, and were more likely to smoke during pregnancy compared to participants who were not dispensed medication in the diary period (Table 1).

\section{Actual use}

A total of 337 prescriptions containing 93 different ATC codes were registered in the pharmacy records with use in the 6-weeks diary period. Table 2 shows the actual use of medications dispensed according to the diaries. Actual use was highest for medication for chronic conditions (88\%, 95\% CI 81-93), followed by pregnancy-related medication (79\%, 95\% CI 71-86) and medication for occasional and short-time use (69\%, 95\% CI 60-77). For the medication groups, actual use ranged between 14\% (asthma rescue medication) and $100 \%$ (antidepressants, asthma maintenance medication, medication for immune-related inflammatory diseases, and thyroid medication). Similar patterns were observed for individual medications, with perfect actual use for citalopram, levothyroxine, and loratadine. Actual use was lowest for combination preparations with meclizine (45\%), topical hydrocortisone (20\%), and salbutamol (14\%).

\section{Initiation}

Prescriptions for 64 pharmacological treatments were dispensed for the first time in the 6-weeks study period, of which $17(27 \%)$ were not initiated. These included 7 prescriptions for pregnancy-related medication, 6 prescriptions for medication for occasional and short-term use, and 4 prescriptions for medication for chronic 
conditions. Of the medications initiated in the diary period $(\mathrm{N}=47), 27(58 \%)$ were started at the same day of the prescription fill (range 0-7 days; Figure 2). The median delay in treatment initiation was 0 days (range 0-6 days) for medication for occasional and short-term use and 1 (range 0-7 days) days for pregnancy-related medication.

\section{Implementation adherence}

Implementation adherence was determined for 218 medications dispensed, of which $66.5 \%$ had [?] $80 \%$ days with at least the correct number of doses taken (Table 3). Overall, implementation adherence was $74.2 \%$ (95\% CI 69.3-79.2). Implementation adherence was high for medication for chronic conditions (86.0\%, 95\% CI 79.592.4), but substantially lower for pregnancy-related medication (74.3\%, 95\% CI 65.6-83.0) and medication for occasional and short-term use (53.7\%, 95\% CI 43.0-64.3). A total of 8 medication groups had [?]80\% days with at least the correct number of doses taken: antidepressants, antiasthmatics, antihypertensive agents, antithrombotic agents, iron preparations, medication for acid-related disorders, medication for immunerelated inflammatory diseases, and thyroid therapy.

We observed a statistically significant difference in implementation adherence to pregnancy-related medication between women aged [?]30 years $(84.2 \%)$ and women aged $>30$ years $(66.2 \%, \mathrm{p}=0.04$; Table 4$)$. Although not statistically significant, implementation adherence differed by more than $10 \%$ for pregnancyrelated medication between women with an income $<\backslash$ euro3,500 and women with an income [?]\euro3,500 ( 81.3 vs. $64.2 \%, \mathrm{p}=0.07$ ). Among women who smoked during pregnancy, implementation was substantially lower for medication for occasional and short-term use (29.4\%) and substantially higher for pregnancyrelated medication $(85.7 \%)$ compared to women who did not smoke during pregnancy $(56.2 \%$ [ $=0.15]$ and $73.0 \%[\mathrm{p}=0.14]$, respectively). No other substantial difference in implementation for the other maternal characteristics we observed.

\section{Correct dosing}

Of the 112 dispensings of medication for chronic conditions, 78 (70\%) were used on [?]80\% of days with at least the correct number of doses, whereas this was the case for $19 \%(20 / 104)$ of medication for occasional or short-term use and 38\% (46/121) of pregnancy-related medication (Figure 3). Correct dosing was most often seen with antidepressants (100\%), asthma maintenance therapy (92\%), thyroid therapy (86\%), and antithrombotic agents (80\%). Incorrect dosing frequently occurred with systemic antibiotics and antimycotics (24\%), topical antibiotics and antifungals (18\%), decongestants (14\%), ear, eye, nose, and throat preparations (11\%), antiemetic medication (7\%), gynecological anti-infectives and antiseptics (7\%), and dermatological corticosteroids $(0 \%)$.

\section{DISCUSSION}

In this prospective study with medication diaries as the reference standard, we observed that majority of medications dispensed were reported to be used, ranging from $69 \%$ (medication for occasional and shortterm use) to $88 \%$ (medication for chronic conditions). A substantial proportion of women, however, did not take the medication as prescribed: the overall implementation adherence was $74.2 \%$. Achieving an implementation adherence of [?] $80 \%$ ranged between $19 \%$ for medication for occasional and short-term use and $70 \%$ for medication for chronic conditions. Implementation adherence of pregnancy-related medication seemed lower for women aged $>30$ years, women with an income [?]\euro3,500, and non-smoking women, whereas women who smoked during pregnancy seemed to have a lower implementation for medication for occasional and short-term use.

Self-report based on interviews or questionnaires is generally acknowledged to result in underreporting of medication use during pregnancy [17-22]. This may explain why the proportion of medications dispensed that is actually reported to be taken is higher in the current study compared with previous studies, in which this measure ranged between 43 and $57 \%$ [14, 19]. However, consistent patterns of actual use are observed between studies when focusing on individual medications or groups of medications, with high levels of actual use for medication for chronic conditions, and substantially lower for medication for occasional and 
short-term use [14, 15, 19-21, 31-34]. Part of these lower levels of actual use for medication for occasional and short-term use may be explained by forgetfulness when using interviews or questionnaires that cover a prolonged period of pregnancy [22], but remained when using diaries as reference standard [21]. This disagreement may be worrisome for some maternal conditions, including infections (antibiotics) and fever (antipyretics), in which pharmacological treatment is often recommended to prevent maternal and infant morbidity and mortality [35-38]. In an Italian cross-sectional study, $3.2 \%$ of women reported intentionally avoiding a prescribed antibiotic in pregnancy [39].

Although actual use gives an indication of medication adherence among pregnant women, it does not assess whether medication is actually used as prescribed in terms of timing and dosage. As human fetal development is strictly sequenced with specific organ systems being formed at particular stages of pregnancy, timing of exposure is of utmost importance when assessing medication safety in pregnancy. In the current study, $42 \%$ of medications were not initiated on the date of prescription fill, but 1-7 days afterwards. These relatively small differences may result in exposure misclassification for the etiologically relevant time window when relying on prescription databases.

In our study, suboptimal implementation adherence could result from two distinct deviations of prescription instructions: an incorrect dosage and a shorter duration of use (persistence). Comparable to our study, de Jonge et al. [16] observed that a substantial proportion of women $(30 \%)$ did not adhere to treatment recommendations, often using a lower dose or for a shorter duration than prescribed. Inadequate treatment of infections and pregnancy-related and chronic conditions, such as hypothyroidism [40], asthma [41], and diabetes [42], is associated with increased risk of adverse birth outcomes. Therefore, adequate and continuous dosage should be aimed for during pregnancy.

To date, there is no strong evidence for certain maternal and pregnancy characteristics to be associated with not following treatment recommendations. In addition to the associations with maternal age, household income, and smoking observed in this study, others identified associations with educational level, marital status, disease severity, and alcohol consumption [19-21, 31, 39, 43]. None of these findings have consistently been reported; only smoking status has been implicated in multiple studies [19, 20]. Identification of characteristics linked to non-adherence may facilitate the implementation of personalized preventive measures.

The clinical implications of non-adherence are relatively straightforward: it may endanger maternal and child health and increase healthcare costs $[2,3]$. Enhancing adherence among pregnant women, however, is not straightforward. Improved counseling may attenuate some of the incorrect risk perceptions of medication safety among pregnant women, but for many medications, robust data on fetal safety are lacking [44-48]. This may hamper evidence-based decisions on whether the potential risks of pharmacological treatment outweigh the burden of the underlying maternal condition. Non-adherence also affects research on medication safety in pregnancy, as many studies rely on administrative databases for exposure assessment [23]. Not taking medication as prescribed, or not taking the medication at all, will lead to exposure misclassification and may bias studies determining associations with infant outcomes [49].

A major strength of the current study is the use of a diary to assess actual medication use, thereby reducing the probability of underreporting due to forgetfulness [24, 25]. The amount of details collected with these diaries enabled us to look beyond actual use by assessing initiation and implementation. Furthermore, the study population was considered large compared to some earlier studies, but still limited in the ability to assess adherence to individual medications and associations between maternal characteristics and implementation. Another limitation includes the relatively short time frame of only 6 weeks in mid-pregnancy. Adherence is expected to be lower in the first trimester of pregnancy because of fear for teratogenicity, but it was considered not feasible to administer diaries immediately after inclusion in the PRIDE Study until delivery due to participant burden. Mobile applications to daily record medication intake may improve the feasibility of intensive long-term data collection [50]. Social desirability might have increased reporting of medication use when not actually taken, but was considered unlikely as participants were unaware of the aim of this study. Also, we were unable to distinguish between intentional and unintentional avoidance of medication use. Some women may have discontinued treatment or implemented dose changes following 
consultation with a healthcare professional before the registered end date of the prescription, which may have decreased implementation adherence unjustly.

In conclusion, actual use of medication dispensed during pregnancy was high in this study compared with previous studies, but many women did not adhere to treatment recommendations regarding dosage and therapy duration. As this behavior may be detrimental to maternal and fetal health, future efforts should focus on identifying reasons for non-adherence and associated preventive measures. Furthermore, the results of this studies may inform and facilitate quantitative bias analyses in studies on medication safety in pregnancy relying on administrative databases or registries.

\section{REFERENCES}

1. World Health Organization. Adherence to long-term therapies: evidence for action. 2003. https://apps.who.int/iris/bitstream/handle/10665/42682/9241545992.pdf. Accessed 13 Jan 2022.

2. Brown MT, Bussell J, Dutta S, Davis K, Strong S, Mathew S. Medication adherence: truth and consequences. Am J Med Sci. 2016;351:387-99. https://doi.org/10.1016/j.amjms.2016.01.010.

3. Osterberg L, Blaschke T. Adherence to medication. N Engl J Med. 2005;353:487-97. https://doi.org/10.1056/nejmra050100.

4. Matsui D. Adherence with drug therapy in pregnancy. Obstet Gynecol Int. 2012;2012:796590. https://doi.org/10.1155/2012/796590.

5. Widnes SF, Schjøtt J, Eide GE, Granas AG. Teratogenic risk perception and confidence in use of medicines in pairs of pregnant women and general practitioners based on patient information leaflets. Drug Saf. 2013;36:481-9. https://doi.org/10.1007/s40264-013-0035-9.

6. Amundsen S, Øvrebø TG, Amble NMS, Poole AC, Nordeng H. Risk perception, beliefs about medicines and medical adherence among pregnant and breastfeeding women with migraine: findings from a crosssectional study in Norway. BMJ Open 2019;9:e026690. https://doi.org/10.1136/bmjopen-2018-026690.

7. Gallinger ZR, Rumman A, Nguyen GC. Perceptions and attitudes towards medication adherence during pregnancy in inflammatory bowel disease. J Crohns Colitis. 2016;10:892-7. https://doi.org/10.1093/ecco-jcc/jjw052.

8. Nyholm RS, Andersen JT, Vermehren C, Kaae S. Perceptions of medicine use among pregnant women: an interview-based study. Int J Clin Pharm. 2019;41:1021-30. https://doi.org/10.1007/s11096019-00840-4.

9. Wolgast E, Lindh-Åstrand L, Lilliecreutz C. Women's perceptions of medication use during pregnancy and breastfeeding-A Swedish cross-sectional questionnaire study. Acta Obstet Gynecol Scand. 2019;98:856-64. https://doi.org/10.1111/aogs.13570.

10. Van Gelder MMHJ, Rog A, Bredie SJH, Kievit W, Nordeng H, van de Belt TH. Social media monitoring on the perceived safety of medication use during pregnancy: A case study from the Netherlands. Br J Clin Pharmacol. 2019;85:2580-90. https://doi.org/10.1111/bcp.14083.

11. Bakkebø T, Widnes SF, Aamlid SS, Schjøtt J. Physicians' perception of teratogenic risk and confidence in prescribing drugs in pregnancy-Influence of Norwegian Drug Information Centers. Clin Ther. 2016;38:1102-8. https://doi.org/10.1016/j.clinthera.2016.02.018.

12. Widnes SF, Schjøtt J. Risk perception regarding drug use in pregnancy. Am J Obstet Gynecol. 2017;216:375-8. https://doi.org/10.1016/j.ajog.2016.12.007.

13. Nugraheni G, Sulistyarini A, Zairina E. Beliefs about medicines in pregnancy: a survey using the beliefs about medicines questionnaire in Indonesia. Int J Clin Pharm. 2020;42:57-64. https://doi.org/10.1007/s11096-019-00937-w.

14. Olesen, C, Søndergaard C, Thrane N, Nielsen GL, de Jong-van den Berg L, Olsen J. Do pregnant women report use of dispensed medications? Epidemiology. 2001;12:497-501. https://doi.org/10.1097/00001648-200109000-00006.

15. Cheung K, El Marroun H, Elfrink ME, Jaddoe VWV, Visser LE, Stricker BHC. The concordance between self-reported medication use and pharmacy records in pregnant women. Pharmacoepidemiol Drug Saf. 2017;26:1119-25. https://doi.org/10.1002/pds.4264.

16. De Jonge L, de Walle HEK, de Jong-van den Berg LTW, van Langen IM, Bakker MK. Actual use of 
medications prescribed during pregnancy: a cross-sectional study using data from a population-based congenital anomaly registry. Drug Saf. 2015;38:737-47. https://doi.org/10.1007/s40264-015-0302-z.

17. Newport DJ, Brennan PA, Green P, et al. Maternal depression and medication exposure during pregnancy: comparison of maternal retrospective recall to prospective documentation. BJOG. 2008;115:6818. https://doi.org/10.1111/j.1471-0528.2008.01701.x.

18. Sarangarm P, Young B, Rayburn W, et al. Agreement between self-report and prescription data in medical records for pregnant women. Birth Defects Res A Clin Mol Teratol. 2012;94:153-61. https://doi.org/10.1002/bdra.22888.

19. Van Gelder MMHJ, van Rooij IALM, de Walle HEK, Roeleveld N, Bakker MK. Maternal recall of prescription medication use during pregnancy using a paper-based questionnaire: a validation study in the Netherlands. Drug Saf. 2013;36:43-54. https://doi.org/10.1007/s40264-012-0004-8.

20. Pisa FE, Casetta A, Clagnan E, Michelesio E, Brumatti LV, Barbone F. Medication use during pregnancy, gestational age and date of delivery: agreement between maternal self-reports and health database information in a cohort. BMC Pregnancy Childbirth. 2015;15:310. https://doi.org/10.1186/s12884-0150745-3.

21. Sundermann AC, Hartmann KE, Jones SH, Torstenson ES, Velez Edwards DR. Validation of maternal recall of early pregnancy medication exposure using prospective diary data. Ann Epidemiol. 2017;27:135-9.e2. https://doi.org/10.1016/j.annepidem.2016.11.015.

22. Van Gelder MMHJ, Vorstenbosch S, te Winkel B, van Puijenbroek EP, Roeleveld N. Using Web-based questionnaires to assess medication use during pregnancy: a validation study in 2 prospectively enrolled cohorts. Am J Epidemiol. 2018;187:326-36. https://doi.org/10.1093/aje/kwx239.

23. Andrade SE, Bérard A, Nordeng HME, Wood ME, van Gelder MMHJ, Toh S. Administrative claims data versus augmented pregnancy data for the study of pharmaceutical treatments in pregnancy. Curr Epidemiol Rep. 2017;4:106-16. https://doi.org/10.1007/s40471-017-0104-1.

24. Verbrugge LM. Health diaries. Med Care. 1980;18:73-95. https://doi.org/10.1097/00005650-19800100000006 .

25. McColl E. Best practice in symptom assessment: a review. Gut. 2004;53(Suppl 4):iv49-54. https://doi.org/10.1136/gut.2003.034355.

26. Van Gelder MMHJ, Merkus PJFM, van Drongelen J, Swarts JW, van de Belt TH, Roeleveld N. The PRIDE Study: evaluation of online methods of data collection. Paediatr Perinat Epidemiol. 2020;34:48494. https://doi.org/10.1111/ppe.12618.

27. KNMP Apothekersorganisatie K. Gebruik van het LSP. https://www.knmp.nl/praktijkvoering/lspzorginfrastructuur/gebruik-van-het-lsp. Accessed 13 Jan 2022.

28. WHO Collaborating Centre for Drug Statistics Methodology. ATC/DDD Index 2021. 2020. https://www.whocc.no/atc_ddd_index/. Accessed 16 March 2021.

29. Bakker MK, Jentink J, Vroom F, Van Den Berg PB, De Walle HEK, De Jong-Van Den Berg LTW. Drug prescription patterns before, during and after pregnancy for chronic, occasional and pregnancy-related drugs in the Netherlands. BJOG. 2006;113:559-68. https://doi.org/10.1111/j.1471-0528.2006.00927.x.

30. Vrijens B, De Geest S, Hughes DA, et al. A new taxonomy for describing and defining adherence to medications. Br J Clin Pharmacol. 2012;73:691-705. https://doi.org/10.1111/j.1365-2125.2012.04167.x.

31. Palmsten K, Hulugalle A, Bandoli G, et al. Agreement between maternal report and medical records during pregnancy: medications for rheumatoid arthritis and asthma. Paediatr Perinat Epidemiol. 2018;32:68-77. https://doi.org/10.1111/ppe.12415.

32. De Jong-van den Berg LTW, Waardenburg CM, Haaijer-Ruskamp FM, Dukes MNG, Wesseling H. Drug use in pregnancy: a comparative appraisal of data collecting methods. Eur J Clin Pharmacol. 1993;45:9-14. https://doi.org/10.1007/bf00315343.

33. Stephansson O, Granath F, Svensson T, Haglund B, Ekbom A, Kieler H. Drug use during pregnancy in Sweden - assessed by the Prescribed Drug Register and the Medical Birth Register. Clin Epidemiol. 2011;3:43-50. https://doi.org/10.2147/clep.s16305.

34. Espnes MG, Bjørge T, Engeland A. Comparison of recorded medication use in the Medical Birth Registry of Norway with prescribed medicines registered in the Norwegian Prescription Database. 
Pharmacoepidemiol Drug Saf. 2011;20:243-8. https://doi.org/10.1002/pds.2085.

35. Bai L, Zhao D, Cheng Q, et al. Trimester-specific association between antibiotics exposure during pregnancy and childhood asthma or wheeze: the role of confounding. Ann Epidemiol. 2019;30:1-8. https://doi.org/10.1016/j.annepidem.2018.10.003.

36. Smaill FM, Vazquez JC. Antibiotics for asymptomatic bacteriuria in pregnancy. Cochrane Database Syst Rev 2019;2019:CD000490. https://doi.org/10.1002/14651858.cd000490.pub4.

37. Antoun S, Ellul P, Peyre H, et al. Fever during pregnancy as a risk factor for neurodevelopmental disorders: results from a systematic review and meta-analysis. Mol Autism. 2021;12:60. https://doi.org/10.1186/s13229-021-00464-4.

38. Dreier JW, Nybo Andersen AM, Berg-Beckhoff G. Systematic review and meta-analyses: fever in pregnancy and health impacts in the offspring. Pediatrics. 2014;133:e674-88. https://doi.org/10.1542/peds.2013-3205.

39. Lupattelli A, Picinardi M, Cantarutti A, Nordeng H. Use and intentional avoidance of prescribed medications in pregnancy: a cross-sectional, Web-based study among 926 women in Italy. Int J Environ Res Public Health. 2020;17:3830. https://doi.org/10.3390/ijerph17113830.

40. Abalovich M, Gutierrez S, Alcaraz G, Maccallini G, Garcia A, Levalle O. Overt and subclinical hypothyroidism complicating pregnancy. Thyroid. 2002;12:63-8. https://doi.org/10.1089/105072502753451986.

41. Yland JJ, Bateman BT, Huybrechts KF, et al. Perinatal outcomes associated with maternal asthma and its severity and control during pregnancy. J Allergy Clin Immunol Pract. 2020;8:1928-37.e3. https://doi.org/10.1016/j.jaip.2020.01.016.

42. Buschur EO, Polsky S. Type 1 diabetes: management in women from preconception to postpartum. J Clin Endocrinol Metab. 2021;106:952-67. https://doi.org/10.1210/clinem/dgaa931.

43. Santa C, Milheiro Tinoco E, Barreira P, Lima R. Predictive factors of non-adherence to asthma medication in pregnancy. Eur Ann Allergy Clin Immunol. 2021. https://doi.org/10.23822/eurannaci.17641489.201.

44. Adam MP, Polifka JE, Friedman JM. Evolving knowledge of the teratogenicity of medications in human pregnancy. Am J Med Genet C Semin Med Genet. 2011;157:175-82. https://doi.org/10.1002/ajmg.c.30313.

45. Thorpe PG, Gilboa SM, Hernandez-Diaz S, et al. Medications in the first trimester of pregnancy: most common exposures and critical gaps in understanding fetal risk. Pharmacoepidemiol Drug Saf. 2013;22:1013-8. https://doi.org/10.1002/pds.3495.

46. Van Gelder MMHJ, de Jong-van den Berg LTW, Roeleveld, N. Drugs associated with teratogenic mechanisms. Part II: a literature review of the evidence on human risks. Hum Reprod. 2014;29:168-83. https://doi.org/10.1093/humrep/det370.

47. Byrne JJ, Saucedo AM, Spong CY. Evaluation of drug labels following the 2015 Pregnancy and Lactation Labeling Rule. JAMA Network Open 2020;3:e2015094. https://doi.org/10.1001/jamanetworkopen.2020.15094.

48. Caritis SN, Venkataramanan R. Obstetrical, fetal, and lactation pharmacology-a crisis that can no longer be ignored. Am J Obstet Gynecol. 2021;225:10-20. https://doi.org/10.1016/j.ajog.2021.02.002.

49. Wood ME, Chrysanthopoulou S, Nordeng HME, Lapane KL. The impact of nondifferential exposure misclassification on the performance of propensity scores for continuous and binary outcomes: a simulation study. Med Care. 2018;56:e46-53. https://doi.org/10.1097/mlr.0000000000000800.

50. Stephansson, O. How to improve information on medication exposure during pregnancy. Paediatr Perinat Epidemiol. 2018;32:78-80. https://doi.org/10.1111/ppe.12431.

\section{FIGURE CAPTIONS}

Fig. 1 Flow chart of participation

Fig. 2 Delay in treatment initiation after a medication dispensing $(\mathrm{N}=47)$

Fig. 3 Adherence to prescribed medication among pregnant women in the six weeks diary period. Only medication groups with [?]10 prescriptions are shown. No actual use indicates that use was not reported in 
the medication diary. Implementation is represented as proportion of days with at least the correct number of doses taken. Implementation adherence was not assessed when medication was prescribed on an as-needed basis or when the dosage was not registered in the pharmacy record

\section{Hosted file}

Adherence_Table 1.docx available at https://authorea.com/users/460064/articles/556140-dopregnant-women-use-pharmacological-treatment-as-prescribed

\section{Hosted file}

Adherence_Table 2.docx available at https://authorea.com/users/460064/articles/556140-dopregnant-women-use-pharmacological-treatment-as-prescribed

\section{Hosted file}

Adherence_Table 3.docx available at https://authorea.com/users/460064/articles/556140-dopregnant-women-use-pharmacological-treatment-as-prescribed

\section{Hosted file}

Adherence_Table 4.docx available at https://authorea.com/users/460064/articles/556140-dopregnant-women-use-pharmacological-treatment-as-prescribed

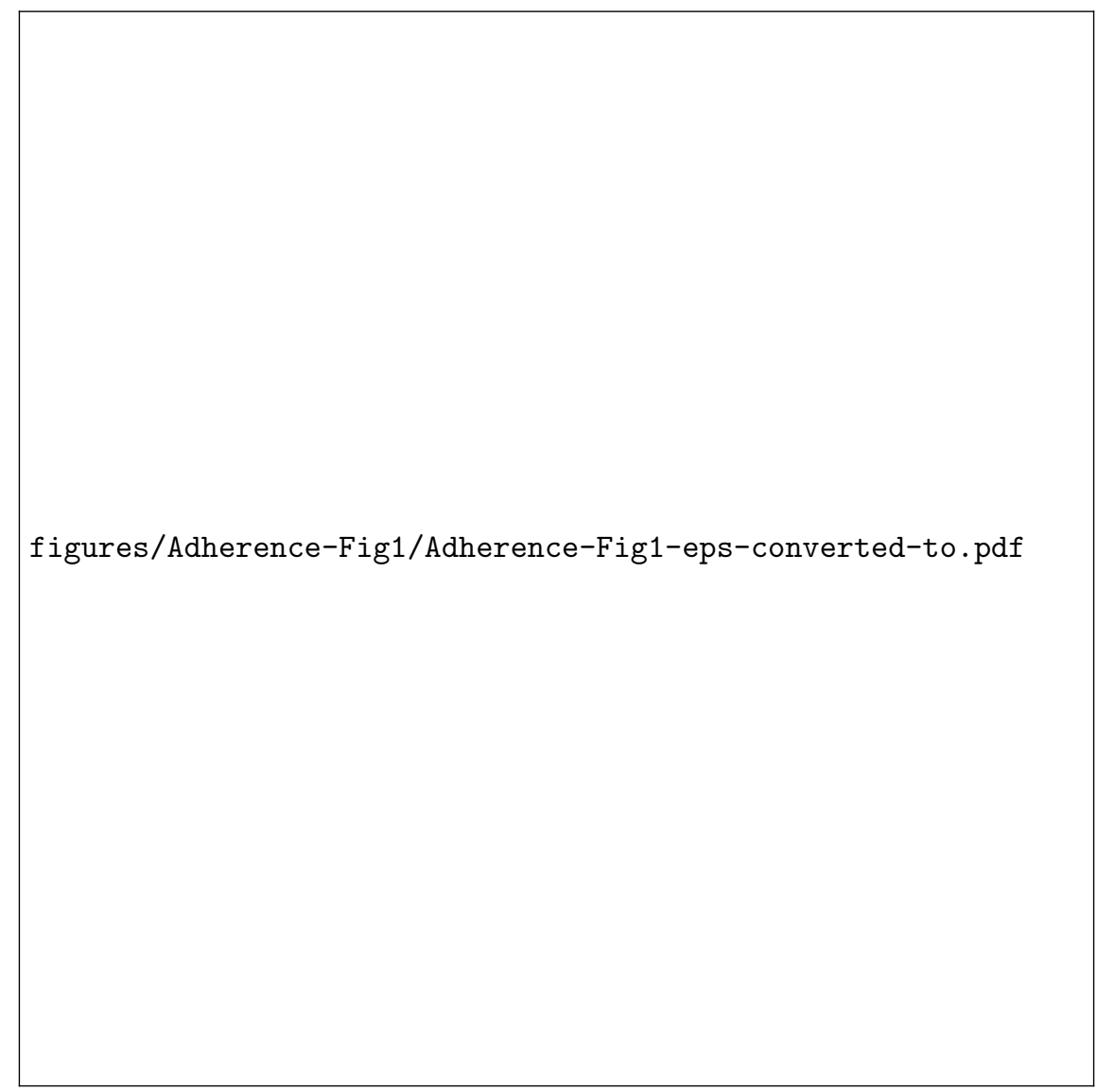


figures/Adherence-Fig2/Adherence-Fig2-eps-converted-to.pdf 
figures/Adherence-Fig3/Adherence-Fig3-eps-converted-to.pdf 